\title{
FATIGUE CRACK GROWTH BEHAVIOR OF VARIOUS STRUCTURAL STEEL AFTER SINGLE AND PERIODIC OVERLOADS
}

\author{
Kentaro YAMADA ${ }^{1}$, Qiuliang $\mathrm{CAO}^{2}$, Yuji OKUHARA ${ }^{3}$ and Xiaohua $\mathrm{CHENG}^{4}$ \\ ${ }^{1}$ Member of JSCE, Ph.D., Professor, Dept. of Civil Eng., Nagoya University (Chikusa-ku, Nagoya 464-01, Japan) \\ ${ }^{2}$ Member of JSCE, Graduate Student, Dept. of Civil Eng., Nagoya University (Chikusa-ku, Nagoya 464-01, Japan) \\ ${ }^{3}$ Member of JSCE, M. Eng., Japan Railway Construction Public Corporation (Ayase 2-12, Adachi-ku, Tokyo, Japan) \\ ${ }^{4}$ Member of JSCE, Dr. Eng., Bridge Division, Public Works Research Institute, Ministry of Construction (Asahi 1,
} Tsukuba 305, Japan)

\begin{abstract}
In order to evaluate accurately fatigue life of weldments under variable amplitude loading, load interaction effect due to load sequence has to be clarified. A simple case is the fatigue crack growth retardation effect resulting from single or periodic overloads. In the present study, fatigue crack growth rates were measured under single and periodic overload conditions on center-cracked tension specimens of structural steel SS400, SM520B and HT780. Effects of several parameters including overload ratio, stress ratio, yield strength of material and interval between overloads on fatigue crack growth retardation were investigated.
\end{abstract}

\section{Key Words: fatigue crack growth rate, load interaction, fatigue crack growth retardation, overload}

\section{INTRODUCTION}

With the increase of traffic in recent years, fatigue cracks were observed in various parts of highway bridges in the past few decades ${ }^{1)}$. Due to the characteristic loading spectra, the fatigue lives of highway bridges normally fall into the long life region. In order to meet the requirements of the design and maintenance of these bridges, fatigue lives of bridge components under variable amplitude (VA) loading in the long life region must be clarified. However, in this region few fatigue test data are available because of long testing time and high cost involved, which leaves the fatigue life prediction in long life region still uncertain.

Currently, relatively simple and conservative fatigue design procedure is often recommended in fatigue design specifications. For example, in the specification proposed by Japanese Society of Steel Construction (JSSC) ${ }^{2}$, VA fatigue life between constant amplitude (CA) fatigue limit and VA cut off limit is defined by linear extension from that in short life region. However in this way, there seem to be two aspects yet to be considered. The first is to evaluate the long VA fatigue lives of weldments under various loading patterns. It was discussed previously based on the fracture mechanics analysis considering various loading histograms and the scatter in initial conditions $^{3)}$. The second aspect is to evaluate the load interaction effect on long VA fatigue life. We often experience that fatigue lives of weldments under VA stress cycles are longer than those predicted by the fracture mechanics without load interaction. Generally in fracture mechanics analysis, the load interaction effect is due to the fatigue crack growth retardation associated with high-low load sequence. It is normally neglected in the present fatigue design specifications. The prediction will be more accurate, if one can model such load sequence effect in the fatigue life prediction model. The present study is among a series of experimental studies in order to establish this kind of model.

Crack closure concept provided by Elber in $1971^{4)}$ gives a good explanation for fatigue crack growth retardation behavior. According to this concept, the remaining plastic deformation on the crack wake causing crack closure is a significant factor of fatigue crack growth retardation. Different loading conditions and material properties affect the crack-tip plastic zone and therefore the remaining plastic deformation on the crack wake. This leads to different amount of fatigue crack growth retardation effect. This study aims at clarifying the effects of loading conditions and material properties on the fatigue crack growth retardation behavior. Some observations and analyses have been reported 
Table 1 Mechanical properties and chemical composition

\begin{tabular}{l|ccc|cccccccccccc}
\hline & \multicolumn{10}{|c|}{ Mechanical Properties } & \multicolumn{10}{c}{ Chemical Composition (\%) } \\
\cline { 2 - 15 } Steel & $\begin{array}{c}\text { Yield } \\
\text { Strength } \\
(\mathrm{MPa})\end{array}$ & $\begin{array}{c}\text { Tensile } \\
\text { Strength } \\
(\mathrm{MPa})\end{array}$ & $\begin{array}{c}\text { Elongation } \\
(\%)\end{array}$ & $\mathrm{C}$ & $\mathrm{Si}$ & $\mathrm{Mn}$ & $\mathrm{P}$ & $\mathrm{S}$ & $\mathrm{Cu}$ & $\mathrm{Ni}$ & $\mathrm{Cr}$ & $\mathrm{Mo}$ & $\mathrm{V}$ \\
\hline SS400 & 351 & 452 & 28 & 0.12 & 0.14 & 0.44 & 0.020 & 0.013 & 0.18 & 0.07 & 0.07 & 0.02 & 0.10 \\
\hline SM520B & 402 & 539 & 24 & 0.16 & 0.34 & 1.32 & 0.014 & 0.006 & - & - & - & - & 0.04 \\
\hline HT780 & 833 & 847 & 26 & 0.06 & 0.26 & 1.34 & 0.007 & 0.002 & 0.97 & 1.03 & 0.46 & 0.31 & 0.04 \\
\hline
\end{tabular}

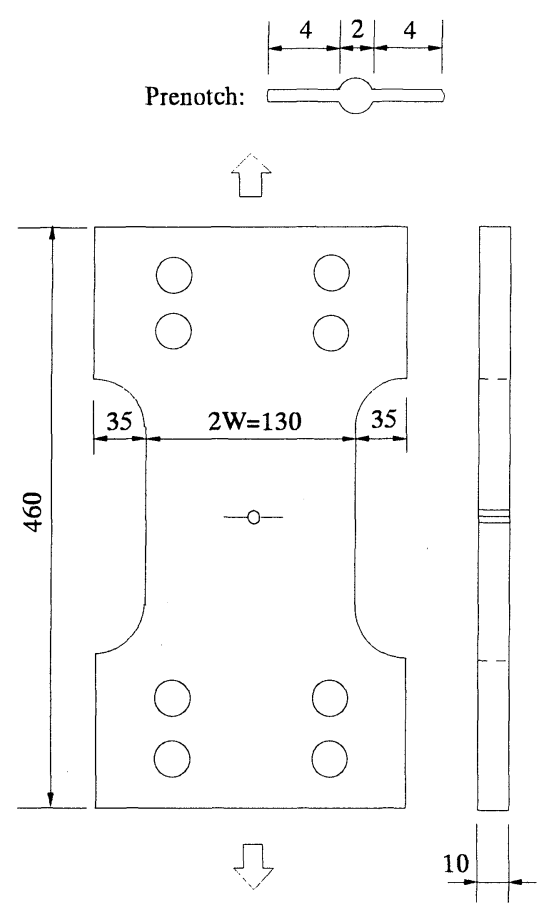

(Unit: mm)

Fig. 1 CCT specimen

elsewhere ${ }^{5)}$. In this study, fatigue tests were carried out on center-cracked tension (CCT) specimens of three types of structural steel, i.e., SM520B, SS400 and HT780. Fatigue crack growth rates were measured under CA loading as well as single overload (SOL) and periodic overload (POL) conditions. Four parameters were focused on to investigate the fatigue crack growth retardation effect. They were: (1) overload ratio, $R_{O L}=\sigma_{O L} / \sigma_{\max },(2)$ stress ratio, $R=\sigma_{\min } / \sigma_{\max }$, (3) yield strength of material, $\sigma_{y}$ and (4) overload interval, $N_{b}$, i.e., the number of cycles between two subsequent overloads in a POL test.

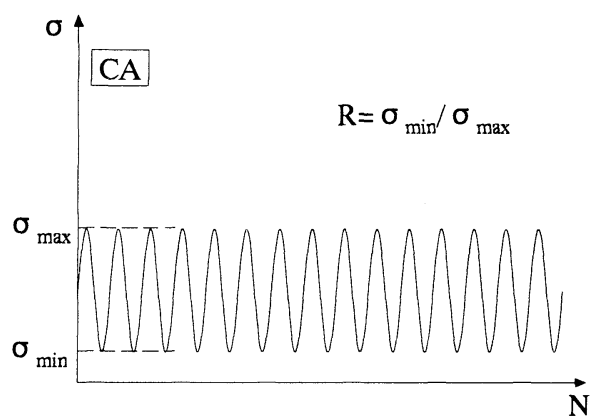

(a) CA Loading

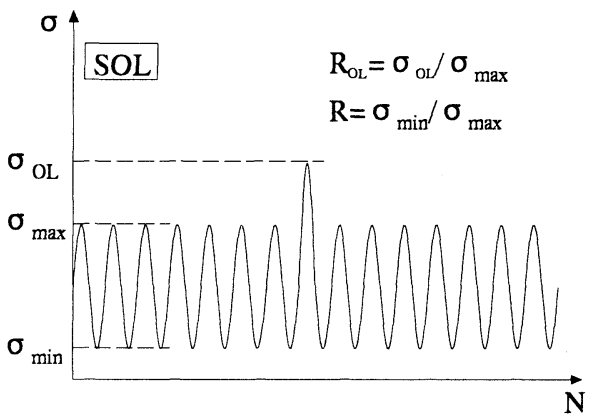

(b) SOL Loading

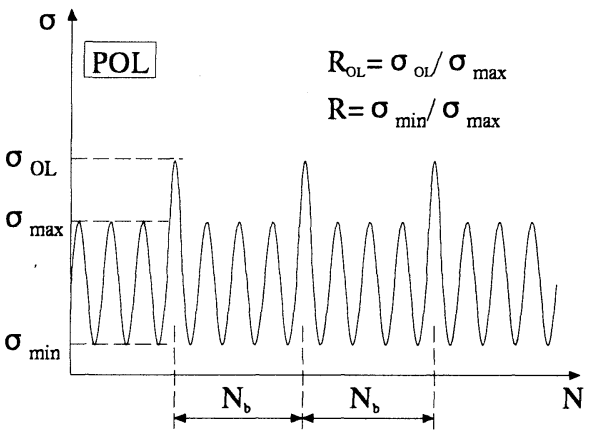

(c) POL Loading

Fig. 2 Typical loading patterns used in the tests 
Table 2 Specimens and loading conditions in CA and SOL tests

\begin{tabular}{c|l|c|c|c|c|c|c}
\hline Steel & Test No. & $\Delta \sigma(\mathrm{MPa})$ & $\sigma_{\max }(\mathrm{MPa})$ & $\sigma_{\min }(\mathrm{MPa})$ & $R$ & $R_{O L}$ & $\sigma_{O L}(\mathrm{MPa})$ \\
\hline \multirow{5}{*}{ SM520B } & SMA-CA & & & & & - & - \\
& SMA-OLH & 70 & 90 & 20 & 0.22 & 2.0 & 180 \\
& SMA-OLM & & & & & 1.7 & 153 \\
& SMA-OLL & & & & & 1.4 & 126 \\
\cline { 2 - 8 } & SMB-CA & & & & & - & - \\
& SMB-OLL & 70 & 130 & 60 & 0.46 & 1.4 & 182 \\
& SMB-OLLL & & & & & 1.2 & 156 \\
\cline { 2 - 8 } & SMC-CA & & & & & - & - \\
& SMC-OLH & 50 & 64 & 14 & 0.22 & 2.0 & 128 \\
& SMC-OLM & & & & & 1.7 & 109 \\
\hline \multirow{5}{*}{ SS400 } & SSA-CA & 70 & 90 & 20 & 0.22 & - & - \\
& SSA-OLL & 70 & 90 & 20 & 0.22 & 1.4 & 126 \\
\cline { 2 - 8 } & SSC-OLL & 50 & 64 & 14 & 0.22 & 1.4 & 90 \\
\cline { 2 - 8 } & SSD-CA & 50 & 93 & 43 & 0.46 & - & - \\
& SSD-OLL & 50 & 93 & 43 & 0.46 & 1.4 & 130 \\
\hline \multirow{3}{*}{ HT780 } & HTA-CA & 70 & 90 & 20 & 0.22 & - & - \\
\cline { 2 - 8 } & HTC-OLL & 50 & 64 & 14 & 0.22 & 1.4 & 90 \\
\cline { 2 - 8 } & HTD-OLL & 50 & 93 & 43 & 0.46 & 1.4 & 130 \\
\hline
\end{tabular}

Table 3 Specimens and loading conditions in POL tests

\begin{tabular}{c|c|c|c|c|c|c|c|c}
\hline Steel & Test No. & $\Delta \sigma(\mathrm{MPa})$ & $\sigma_{\max }(\mathrm{MPa})$ & $\sigma_{\min }(\mathrm{MPa})$ & $R$ & $R_{O L}$ & $\sigma_{O L}(\mathrm{MPa})$ & $N_{b}$ \\
\hline SM520B & SMC-POM5 & 50 & 64 & 14 & 0.22 & 1.7 & 109 & $5 \times 10^{3}$ \\
SM520B & SMC-POM20 & 50 & 64 & 14 & 0.22 & 1.7 & 109 & $2 \times 10^{4}$ \\
\hline
\end{tabular}

\section{EXPERIMENT OUTLINE}

\section{(1) Test specimens}

Fatigue crack growth rates were measured on CCT specimens of structural steel SM520B, SS400 and HT780. The mechanical properties and the chemical composition of the steel are listed in Table 1. The shape and dimension of the specimens are shown in Fig. 1. The prenotch, which is $10 \mathrm{~mm}$ wide for SM520B and SS400 and 20mm wide for HT780, was manufactured by electro-discharge machining. Both surfaces of specimen were mirror-polished for easy observation of fatigue crack tip by microscopes. A $3 \mathrm{~mm}$-long pre-crack originating from each end of the prenotch was made under CA loading before the fatigue crack growth measurement started.

\section{(2) Loading patterns}

The typical loading patterns of CA, SOL and POL are shown in Fig. 2. The loading conditions for each test are listed in Tables $\mathbf{2}$ and $\mathbf{3}$.

For CA and SOL loading, specimens were tested under four stress levels, A, B, C and D, and four overload ratios, OLH, OLM, OLL and OLLL. Overloads were applied twice or three times at different stages of fatigue crack growth.

For POL loading, fatigue test was carried out on one SM520B specimen with stress level $\mathrm{C}$ and overload ratio OLM. The interval between overloads was first $5 \times 10^{3}$ cycles (SMC-POM5) and then $2 \times$ $10^{4}$ cycles (SMC-POM20). Before the overload application with interval of $2 \times 10^{4}$ cycles, fatigue crack growth rate was temporarily recovered to that of CA.

\section{(3) Test procedure}

The experimental procedure was almost the same as that in the previous tests described in Ref. 5. The fatigue crack sizes were measured periodically at every $3 \times 10^{3}$ cycles or less around the overload. In the region far away from the overload position, fatigue crack sizes were measured before fatigue crack growth increments exceeded $0.5 \mathrm{~mm}$.

\section{(4) Post-processing of test data}

During the tests, crack size $a$ and number of cycles $N$ were recorded. Steady fatigue crack growth was observed when CA loading was applied. However, 
Table 4 Test data in SOL tests

\begin{tabular}{|c|c|c|c|c|c|c|c|c|}
\hline Test No. & O.L. & $\begin{array}{c}\Delta K_{A} \\
(\mathrm{MPa} \sqrt{\mathrm{m}})\end{array}$ & $\begin{array}{l}(d a / d N)_{A} \\
(\mathrm{~m} / \text { cycle })\end{array}$ & $\begin{array}{l}\Delta a_{O L} \\
(\mathrm{~mm})\end{array}$ & $\begin{array}{c}N_{O L} \\
\text { (cycle) }\end{array}$ & $\begin{array}{r}\Delta a_{O L} / N_{O L} \\
(\mathrm{~m} / \text { cycle })\end{array}$ & $\begin{array}{c}\left(\Delta a_{O L} / N_{O L}\right) / \\
(d a / d N)_{A}\end{array}$ & $\begin{array}{c}\rho \\
(\mathrm{mm})\end{array}$ \\
\hline \multirow{3}{*}{ SMA-OLH } & $1 \mathrm{st}$ & 14.003 & $1.727 \times 10^{-8}$ & 0.770 & 89,545 & $8.599 \times 10^{-9}$ & 0.498 & 2.967 \\
\hline & 2nd & 16.060 & $2.683 \times 10^{-8}$ & 2.318 & 171,704 & $1.350 \times 10^{-8}$ & 0.503 & 3.900 \\
\hline & 3 rd & 24.845 & $1.175 \times 10^{-7}$ & 10.601 & 163,873 & $6.469 \times 10^{-8}$ & 0.550 & 9.644 \\
\hline \multirow{3}{*}{ SMA-OLM } & $1 \mathrm{st}$ & 12.583 & $1.042 \times 10^{-8}$ & 1.503 & 267,342 & $5.622 \times 10^{-9}$ & 0.540 & 1.559 \\
\hline & 2nd & 14.487 & $1.825 \times 10^{-8}$ & 1.496 & 134,766 & $1.110 \times 10^{-8}$ & 0.608 & 2.060 \\
\hline & $3 r d$ & 18.049 & $4.401 \times 10^{-8}$ & 3.659 & 121,676 & $3.007 \times 10^{-8}$ & 0.683 & 3.174 \\
\hline \multirow{3}{*}{ SMA-OLL } & $1 \mathrm{st}$ & 12.595 & $1.175 \times 10^{-8}$ & 0.669 & 66,494 & $1.006 \times 10^{-8}$ & 0.856 & 0.946 \\
\hline & 2nd & 14.497 & $1.925 \times 10^{-8}$ & 1.412 & 84,552 & $1.670 \times 10^{-8}$ & 0.868 & 1.248 \\
\hline & $3 \mathrm{rd}$ & 18.053 & $4.006 \times 10^{-8}$ & 2.569 & 70,710 & $3.633 \times 10^{-8}$ & 0.907 & 1.912 \\
\hline \multirow{3}{*}{ SMB-OLL } & $1 \mathrm{st}$ & 12.559 & $1.439 \times 10^{-8}$ & 0.596 & 66,597 & $8.949 \times 10^{-9}$ & 0.622 & 1.280 \\
\hline & 2nd & 14.467 & $2.275 \times 10^{-8}$ & 1.009 & 65,981 & $1.529 \times 10^{-8}$ & 0.672 & 1.692 \\
\hline & $3 \mathrm{rd}$ & 18.039 & $4.217 \times 10^{-8}$ & 1.886 & 65,382 & $2.885 \times 10^{-8}$ & 0.684 & 2.606 \\
\hline \multirow{3}{*}{ SMB-OLLL } & $1 \mathrm{st}$ & 12.969 & $1.283 \times 10^{-8}$ & 0.689 & 54,769 & $1.258 \times 10^{-8}$ & 0.981 & 0.811 \\
\hline & 2nd & 14.893 & $2.079 \times 10^{-8}$ & 0.842 & 41,911 & $2.009 \times 10^{-8}$ & 0.966 & 1.063 \\
\hline & $3 \mathrm{rd}$ & 18.404 & $4.258 \times 10^{-8}$ & 1.820 & 44,293 & $4.109 \times 10^{-8}$ & 0.965 & 1.602 \\
\hline \multirow{3}{*}{ SMC-OLH } & $1 \mathrm{st}$ & 12.606 & $1.110 \times 10^{-8}$ & 2.719 & 547,563 & $4.966 \times 10^{-9}$ & 0.448 & 2.147 \\
\hline & 2nd & 17.246 & $3.340 \times 10^{-8}$ & 3.649 & 230,512 & $1.583 \times 10^{-8}$ & 0.474 & 3.936 \\
\hline & $3 \mathrm{rd}$ & 21.274 & $7.281 \times 10^{-8}$ & 9.222 & 304,458 & $3.029 \times 10^{-8}$ & 0.416 & 6.009 \\
\hline \multirow[t]{2}{*}{ SMC-OLM } & $1 \mathrm{st}$ & 12.933 & $1.200 \times 10^{-8}$ & 0.665 & 105,605 & $6.297 \times 10^{-9}$ & 0.525 & 1.518 \\
\hline & 2nd & 18.452 & $4.291 \times 10^{-8}$ & 1.848 & 84,082 & $2.198 \times 10^{-8}$ & 0.512 & 2.980 \\
\hline \multirow[t]{2}{*}{ SSA-OLL } & $1 \mathrm{st}$ & 14.521 & $1.834 \times 10^{-8}$ & 1.587 & 138,800 & $1.143 \times 10^{-8}$ & 0.623 & 1.684 \\
\hline & 2nd & 20.435 & $6.517 \times 10^{-8}$ & 3.703 & 87,000 & $4.256 \times 10^{-8}$ & 0.653 & 3.280 \\
\hline \multirow{3}{*}{ SSC-OLL } & $1 \mathrm{st}$ & 13.444 & $1.300 \times 10^{-8}$ & 2.463 & 259,887 & $9.477 \times 10^{-9}$ & 0.729 & 1.355 \\
\hline & 2nd & 16.930 & $3.196 \times 10^{-8}$ & 1.569 & 67,587 & $2.321 \times 10^{-8}$ & 0.726 & 2.093 \\
\hline & 3 rd & 25.862 & $1.736 \times 10^{-7}$ & 5.336 & 43,000 & $1.241 \times 10^{-7}$ & 0.715 & 4.769 \\
\hline \multirow{3}{*}{ SSD-OLL } & $1 \mathrm{st}$ & 13.270 & $1.797 \times 10^{-8}$ & 2.046 & 144,696 & $1.414 \times 10^{-8}$ & 0.932 & 1.765 \\
\hline & 2nd & 15.186 & $2.710 \times 10^{-8}$ & 1.935 & 82,681 & $2.340 \times 10^{-8}$ & 0.863 & 2.283 \\
\hline & 3 rd & 16.782 & $4.101 \times 10^{-8}$ & 3.393 & 108,368 & $3.131 \times 10^{-8}$ & 0.905 & 2.761 \\
\hline \multirow{3}{*}{ HTC-OLL } & $1 \mathrm{st}$ & 14.306 & $1.833 \times 10^{-8}$ & 0.430 & 29,445 & $1.461 \times 10^{-8}$ & 0.797 & 0.258 \\
\hline & 2nd & 16.431 & $2.885 \times 10^{-8}$ & 0.915 & 36,498 & $2.507 \times 10^{-8}$ & 0.869 & 0.332 \\
\hline & $3 \mathrm{rd}$ & 21.483 & $1.075 \times 10^{-7}$ & 1.381 & 19,925 & $6.931 \times 10^{-8}$ & 0.819 & 0.536 \\
\hline \multirow{3}{*}{ HTD-OLL } & $1 \mathrm{st}$ & 12.347 & $1.008 \times 10^{-8}$ & 0.458 & 44,509 & $1.029 \times 10^{-8}$ & 0.928 & 0.257 \\
\hline & 2nd & 14.304 & $1.815 \times 10^{-8}$ & 0.838 & 45,464 & $1.843 \times 10^{-8}$ & 0.908 & 0.338 \\
\hline & $3 \mathrm{rd}$ & 16.413 & $3.500 \times 10^{-8}$ & 1.972 & 70,036 & $2.816 \times 10^{-8}$ & 0.929 & 0.436 \\
\hline
\end{tabular}

when an overload was applied the succeeding fatigue crack growth rate dropped down. Then, it gradually recovered to the level corresponding to CA loading. This process is called the fatigue crack growth retardation.

In order to obtain the smooth $a$ versus $N$ curve and the value of $d a / d N$ from the discrete test data, the least-squares polynomial approximation ${ }^{6}$ is employed, in which a parabola is adopted for smoothing overlapping seven data points. In this way, the values of $a, N$ and $d a / d N$ at any point can be obtained ${ }^{\text {t }}$.

A typical $a$ versus $N$ curve obtained through the above data smoothing approach around the overload application in test SMA-OLH is given in Fig. 3 along with the test data. The corresponding $d a / d N$ versus $a$ relationship is shown in Fig. 4. In the figures, $\Delta a_{O L}$ is defined as the overload affected zone, which is the difference between the crack sizes when the overload is applied and when the crack growth rate recovers to that of CA loading. The number of cycles needed to propagate the crack by $\Delta a_{O L}$ is defined as $N_{O L}$. The starting point $\mathrm{A}$ is the position where the overload is applied, and the ending point $B$ is where the corresponding $d a / d N$ reaches the value defined by the 


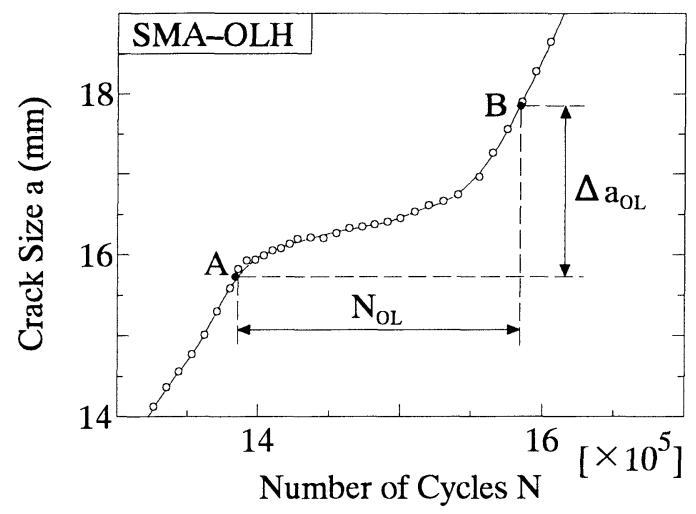

Fig. 3 Typical $a$ versus $N$ curve around overload application

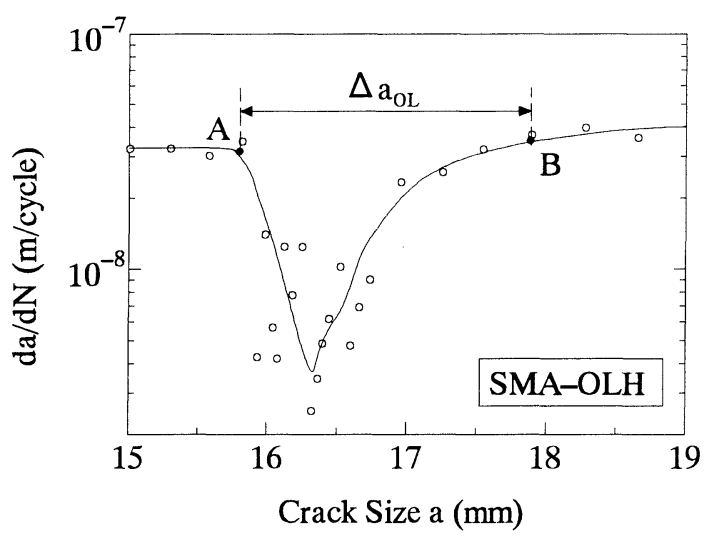

Fig. 4 Typical $d a / d N$ versus $a$ curve around overload application

following equation.

$$
(d a / d N)_{B}=\left(\Delta K_{B} / \Delta K_{A}\right)^{m} \cdot(d a / d N)_{A}
$$

where $\Delta K_{A}$ and $\Delta K_{B}$ are the stress intensity factor ranges at point $\mathrm{A}$ and point $\mathrm{B}$, respectively. They are calculated by Eq. 2 .

$$
\Delta K=\Delta \sigma \cdot \sqrt{\pi a} \cdot \sqrt{\sec \left(\frac{\pi a}{2 W}\right)}
$$

where the first two items define the stress intensity factor range of Griffith crack and the third item is the finite-width correction factor, in which $\mathrm{W}$ is the half specimen width. Because $(d a / d N)_{B}$ is the function of crack size $a$, the so-called trial method is used to locate point $\mathrm{B}$. On the smooth $a$ versus $N$ curve shown in Fig. 3, from the lowest point moving upward, the first point meeting Eq.1 is determined to

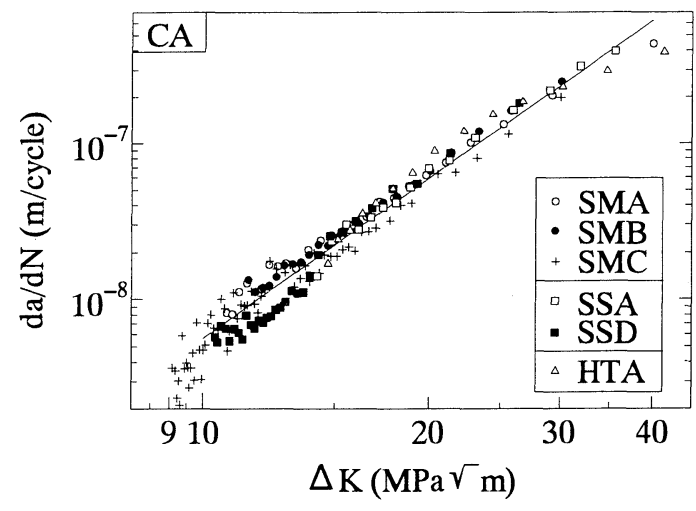

Fig. 5 CA test results

be point $\mathrm{B}$.

\section{CA TEST RESULTS}

Six specimens of SM520B, SS400 and HT780 were used for CA tests. Fig. 5 shows the $d a / d N$ versus $\Delta K$ relationships in the log-log scale. These data were recorded mostly at the $\Delta K$ above $10 \mathrm{MPa} \sqrt{\mathrm{m}}$. It can be seen that the $d a / d N$ for all tests fall within a band, where $d a / d N$ versus $\Delta K$ relationships are approximately linear. The regression analysis of all test data results in the following equation.

$$
d a / d N=C(\Delta K)^{m}, C=2.255 \times 10^{-12}, m=3.398
$$

where the material constants $C$ and $m$ are determined by the least square method.

For SM520 specimens tested at $\Delta \sigma=50 \mathrm{MPa}$ and $R=0.22$, the data below $\Delta K=10 \mathrm{MPa} \sqrt{\mathrm{m}}$ show the tendency of having the effect of threshold-level stress intensity factor range, $\Delta K_{t h}$. The same tendency was observed on the base metal by $\mathrm{NRIM}^{8}$. It should be noted that if the tests are carried out with high stress ratio or with high residual tensile stress near the crack tip, $\Delta K$ will approach the effective stress intensity factor range, $\Delta K_{\text {eff }}$, and $\Delta K_{t h}$ will yield to a lower value, such as $\Delta K_{t h}=2.5 \mathrm{MPa} \sqrt{\mathrm{m}}{ }^{8)}$.

\section{SOL TEST RESULTS}

The values of $\Delta a_{O L}$ and $N_{O L}$ are obtained for each test. Further data processing gives the values of the average crack growth rate, $\Delta a_{O L} / N_{O L}$, in the overload affected zone, and the non-dimensional 


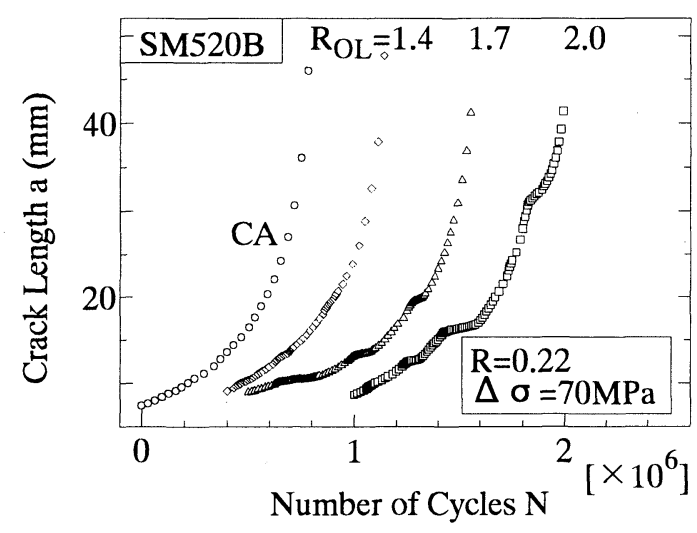

(a) A-series

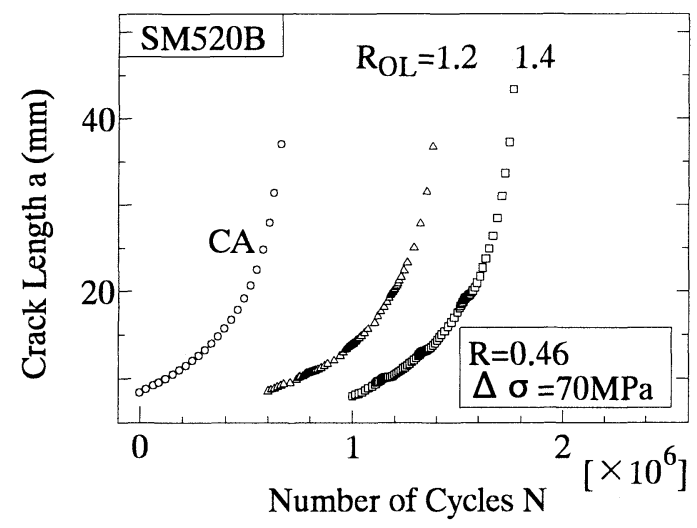

(b) B-series

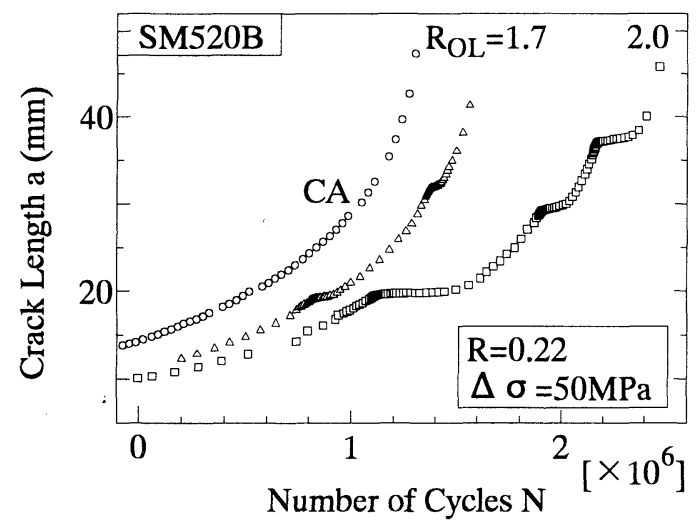

(c) C-series

Fig. 6 Fatigue crack growth behavior of SM520B under CA and SOL

variable $1-\left(\Delta a_{O L} / N_{O L}\right) /(d a / d N)_{A}$, which denotes the relative reduction of fatigue crack growth rate following the overload. The Dugdale's plastic zone

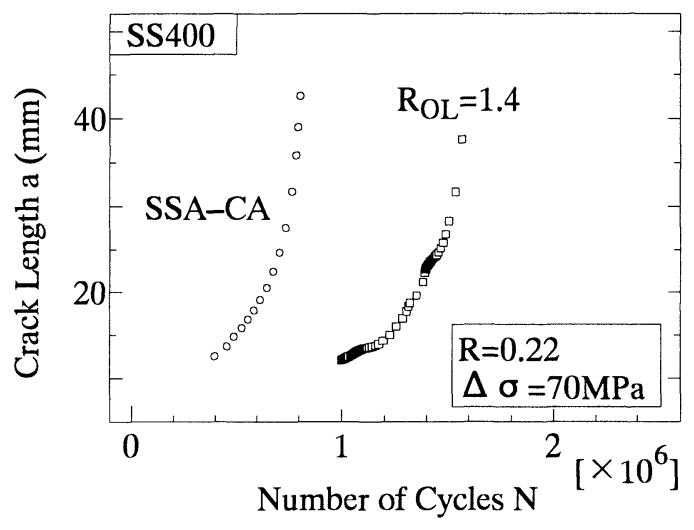

(a) SS400 A-series

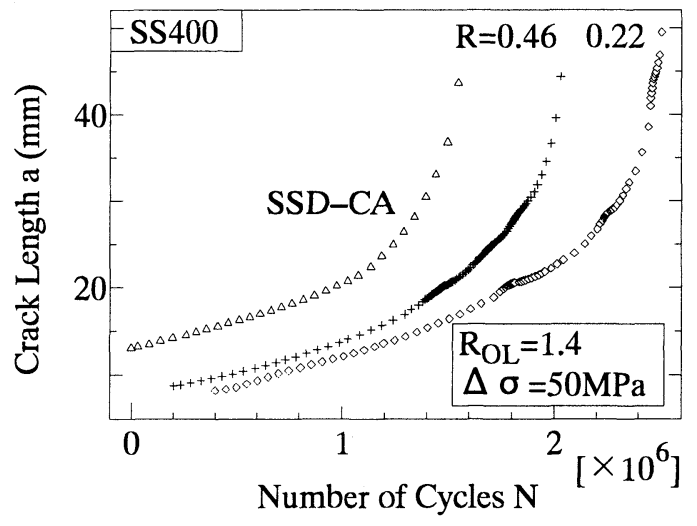

(b) SS400 B, C-series

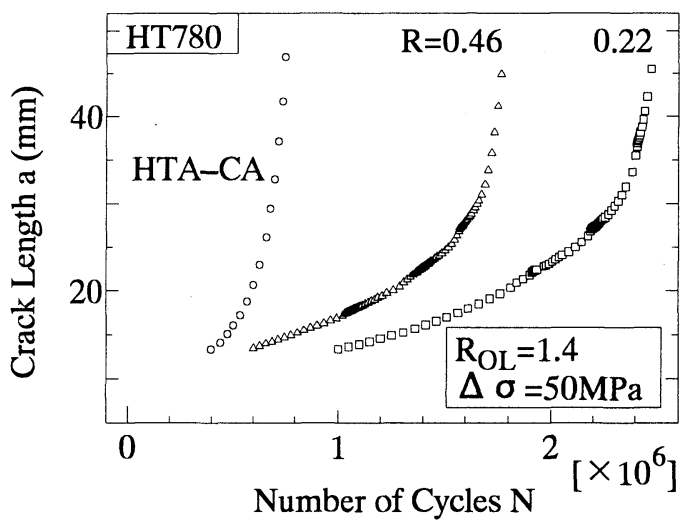

(c) HT780 all series

Fig. 7 Fatigue crack growth behavior of SS400 and HT780 under CA and SOL

sizes ${ }^{9)}$ corresponding to each overload are also calculated for comparison. All of these values are listed in Table 4. 


\section{(1) Fatigue crack growth behavior}

Figure 6 shows $a$ versus $N$ relationships for SM520B tests under three series of loading conditions. The starting points of the data plotted here are shifted either to left or right in order to facilitate easy comparison. From these three figures, the crack growth behavior after overload application can be clearly observed. As described above, the crack growth rate drops down and deviates from that of CA loading at first, and then recovers gradually. Because the stress level, stress ratio and material properties are the same in each series of loading conditions, the difference in the amount of crack growth retardation effect is due to the different overload level, i.e., the value of $R_{O L}$ or $\sigma_{O L}$. It can be noticed that the number of cycles elapsed in the overload affected zone, $N_{O L}$, which represents the amount of crack growth retardation effect here, generally increases with the overload ratio, $R_{O L}$, or the overload value, $\sigma_{O L}$. Moreover, the overload normally produces larger retardation effect, if it is applied in the earlier stage of crack growth.

Similarly, the $a$ versus $N$ relationships for SS400 and HT780 tests are plotted in Fig. 7. In each test, the above-stated fatigue crack growth behavior following the overload can also be found. In addition, SS400 tests show larger retardation effect for those overloads applied in the earlier stage of crack growth, while in HT780 tests this phenomenon seems not evident because all overload affected zone sizes are rather small.

(2) Average fatigue crack growth rate in overload affected zone

Figure 8(a) shows the $\Delta a_{O L} / N_{O L}$ versus $\Delta K_{A}$ relationships in SM520B tests. Here, $\Delta K_{A}$ is the stress intensity factor range right before the overload application. As described above, $\Delta a_{O L}$ is the crack size increment from overload application to the end of crack growth retardation and $N_{O L}$ is the number of cycles elapsed in overload affected zone. Therefore, $\Delta a_{O L} / N_{O L}$ denotes the average crack growth rate in overload affected zone.

From the figure, the following two phenomena are observed. (1) The average crack growth rate in overload affected zone is lower than the CA level, implying that the crack growth retardation does occur. (2) The overload applied in large- $\Delta K_{A}$ region always causes larger value of $\Delta a_{O L} / N_{O L}$ than that applied in small- $\Delta K_{A}$ region. It implies that the average crack growth rate in overload affected zone increases

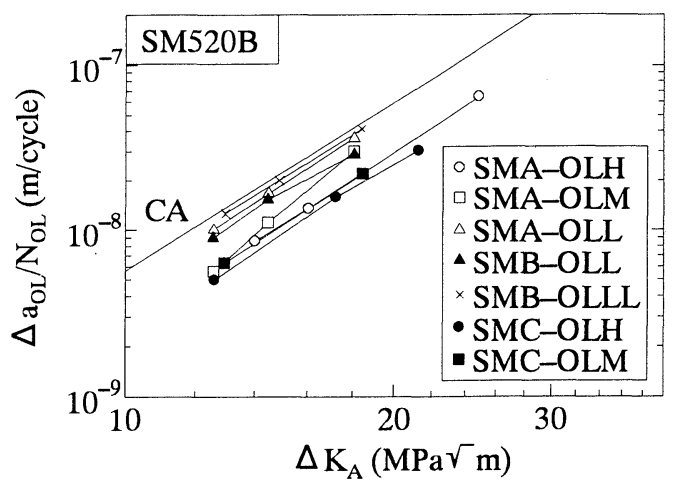

(a) SM520B tests

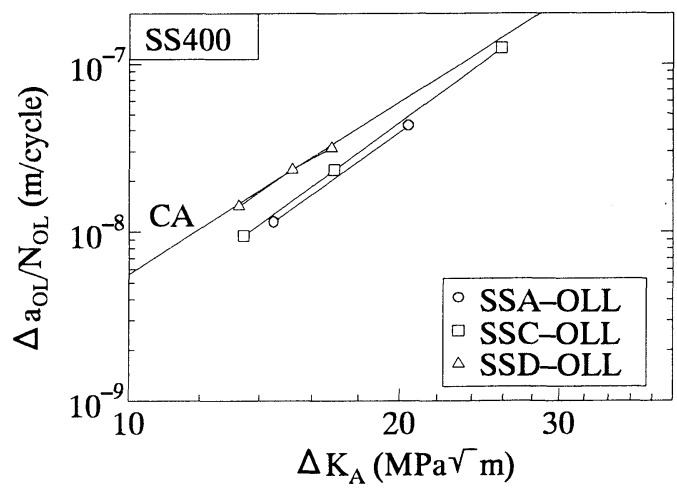

(b) SS400 tests

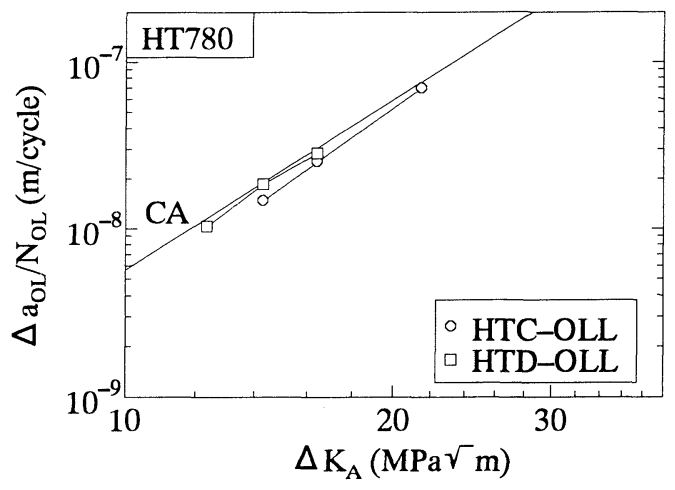

(c) HT780 tests

Fig. 8 Average fatigue crack growth rate in overload affected zone

with $\Delta K_{A}$. In addition, connecting the points corresponding to the two or three overloads in a test approximately produces a straight line with almost the same slope as that of CA loading, i.e., the 


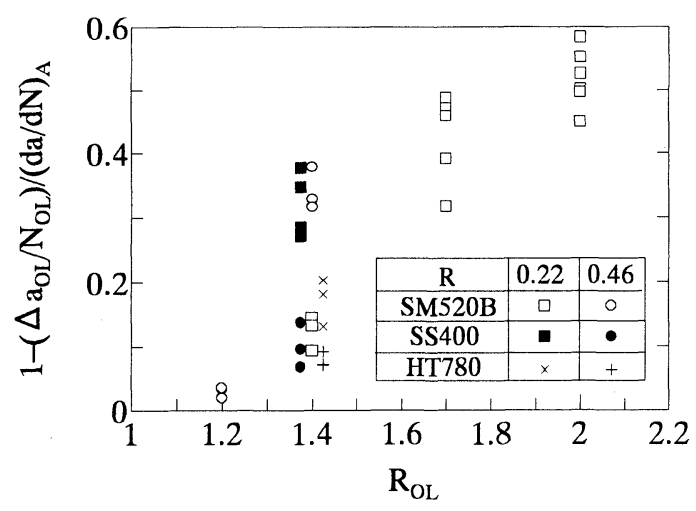

Fig. 9 Relative reduction of fatigue crack growth rate following the overload

absolute reduction of average crack growth rate from CA level resulting from each overload in a SOL test is about the same.

Similarly, $\Delta a_{O L} / N_{O L}$ versus $\Delta K_{A}$ relationships for SS400 and HT780 are plotted in Figs. 8(b) and (c), respectively. The same tendency as stated above is found.

\section{(3) Relative reduction of fatigue crack growth rate following the overload}

In order to compare the test results of different test conditions, the average crack growth rate in overload affected zone, $\Delta a_{O L} / N_{O L}$, is normalized by $(d a / d N)_{A}$, which is the crack growth rate right before the overload application. Obviously the nondimensional variable $1-\left(\Delta a_{O L} / N_{O L}\right) /(d a / d N)_{A}$ represents the relative reduction of fatigue crack growth rate following the overload. The relationship between this value and overload ratio, $R_{O L}$, is shown in Fig. 9 for two levels of stress ratio, $R=0.22$ and 0.46 .

It is known from the figure that the value of $1-\left(\Delta a_{O L} / N_{O L}\right) /(d a / d N)_{A}$ increases with the overload ratio, $R_{O L}$, which implies that higher $R_{O L}$ leads to larger relative reduction of fatigue crack growth rate. For SM520B, the relative reductions at $R_{O L}=1.2,1.4,1.7$ and 2.0 were about $3 \%, 23 \%, 43 \%$ and $52 \%$, respectively. For SS400 and HT780, the relative reductions at $R_{O L}=1.4$ were about $23 \%$ and $14 \%$, respectively.

\section{(4) Comparison between overload affected zone} size and crack-tip plastic zone size

The crack-tip plastic zone size, $\rho$, produced by an overload, plays an important role in determining the retardation effect. Up to now, there have been

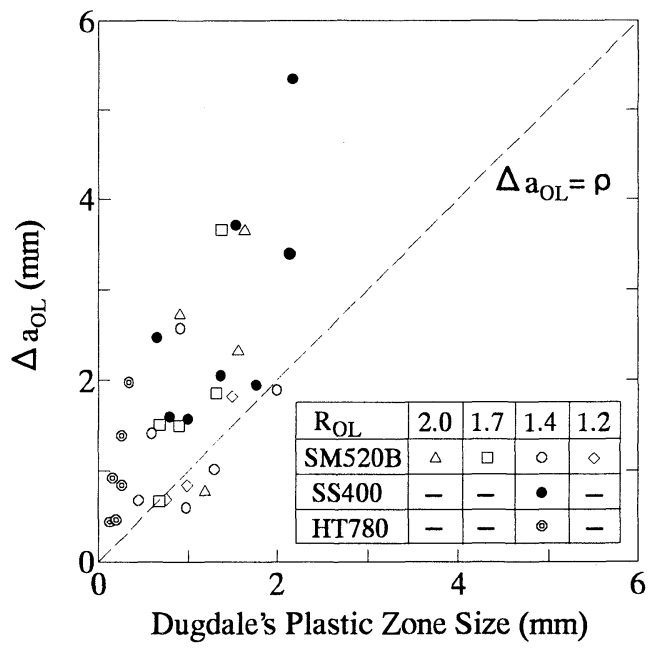

Fig. 10 Comparison between overload affected zone size and Dugdale's plastic zone size

established several ways for calculating the crack-tip plastic zone size, among which Dugdale's expression, given as Eq.3, has received widespread use.

$$
\rho=a\left\{\frac{2 W}{\pi a} \sin ^{-1}\left[\sin \left(\frac{\pi a}{2 W}\right) \sec \left(\frac{\pi \sigma_{O L}}{2 \alpha \sigma_{y}}\right)\right]-1\right\}
$$

where $\alpha$ is the constraint factor that expresses the constraint effect in the direction of plate thickness on the plastic deformation at the crack tip. Here this value is taken as 1.68 , which is the case of planestrain condition ${ }^{10)}$.

In the study, the overload affected zone size, $\Delta a_{O L}$, obtained for each overload is plotted against the Dugdale's plastic zone size in Fig. 10. It can be noticed that almost all of the data points are above the line $\Delta a_{O L}=\rho$, indicating that the overload affected zone sizes are larger than the Dugdale's plastic zone sizes. Especially for HT780, the deviation of the data points from the line seems to be even larger. This means that for HT780 the crack-tip plastic deformation produced by the overload takes relatively longer-term effect compared with the other two types of steel.

\section{(5) Normalized overload affected zone size}

Fig. 11 shows the relationships between $\Delta a_{O L} / \rho$ and stress ratio $R$ for three types of steel at $R_{O L}=1.4$. The value of $\Delta a_{O L} / \rho$ expresses when or where the retardation effect diminishes after the overload application. For each material shown in Fig. 11, this 


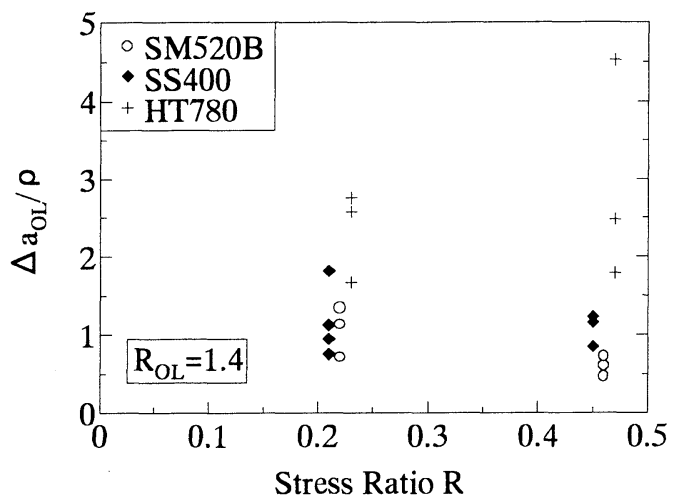

Fig. 11 Normalized overload affected zone size

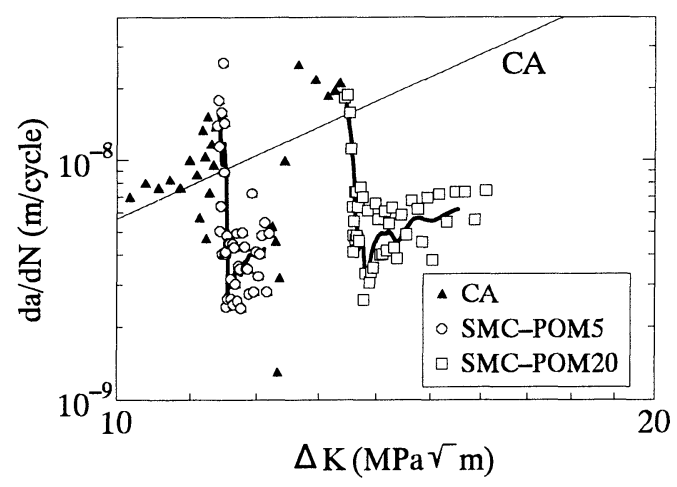

Fig. 12 Effect of overload interval in POL tests

value may represent the amount of crack growth retardation under a certain $R$ level now that all of the other test conditions are the same.

It is noted that HT780 has larger level of $\Delta a_{O L} / \rho$ than SM520B or SS400, which is consistent with the observation from Fig. 10. For SM520B, the average value of this variable decreases from about $100 \%$ to $60 \%$ when $R$ increases from 0.22 to 0.46 , indicating that larger stress ratio leads to less retardation effect. However, for SS400 and HT780, the effect of $R$ becomes less. The value of $\Delta a_{O L} / \rho$ remains almost unchanged even if $R$ increases.

\section{POL TEST RESULTS}

Periodic overloads were first applied in the interval of $5 \times 10^{3}$ cycles and then turned to $2 \times 10^{4}$ cycles. The test data are plotted in Fig. 12. In order to investigate the effect of overload interval in POL tests, the $d a / d N$ versus $\Delta K$ curves for both cases are smoothened in the same way as for SOL tests and are shown in the figure by thick solid curves. During the
Table 5 Regression constants of $d a / d N-\Delta K \quad(m=3.398)$

\begin{tabular}{|l|c|c|}
\hline \multicolumn{1}{|c|}{ Test No. } & $C$ & $\begin{array}{c}\text { Relative } \\
\text { Reduction (\%) }\end{array}$ \\
\hline CA & $2.255 \times 10^{-12}$ & - \\
\hline SMC-POM5 & $8.951 \times 10^{-13}$ & 60 \\
\hline SMC-POM20 & $6.571 \times 10^{-13}$ & 71 \\
\hline
\end{tabular}

test, CA loading was applied twice on the specimen, the test data of which are shown as solid triangles.

It can be seen from the figure that after the first overload of SMC-POM5 is applied, crack growth rate rises up temporarily and then drops down. In case of SOL test, fatigue crack growth rate will finally recover to the CA level once the crack tip grows out of the overload affected zone. However, in case of POL test, the next overload is applied before the crack growth rate recovers to the CA level. Consequently fatigue crack growth rates stay at lower values than those of the $\mathrm{CA}$ case. They fluctuate around a certain level that can be simulated by the Paris' equation given as follows.

$$
d a / d N=C(\Delta K)^{m}
$$

where $m$ is fixed as 3.398 , the value corresponding to CA loading. Constant $C$ for SMC-POM5 and SMCPOM20 obtained through least square approximation are shown in Table 5 along with that of CA loading. It is verified that the relative reductions on constant $C$ for both cases are $60 \%$ and $71 \%$, respectively. It can be understood from this that larger overload interval leads to more crack growth retardation effects under the present test conditions.

\section{SUMMARY}

In the present study, fatigue crack growth behaviors were investigated for CCT specimens of three types of structural steel, including SM520B, SS400 and HT780, after single overload and periodic overloads. The loading conditions were: stress range $\Delta \sigma=50$ and $70 \mathrm{MPa}$, stress ratio $R=0.22$ and 0.46 and overload ratio $R_{O L}=1.2,1.4,1.7$ and 2.0 . Intervals of periodic overloads were $5 \times 10^{3}$ and $2 \times$ $10^{4}$ cycles. The effects of loading conditions and material properties on fatigue crack growth retardation were studied based on the test results and the conclusions are summarized as follows.

(1) Fatigue crack growth retardation was found in all SOL and POL tests. The amount of retardation effects depended on various loading conditions and material properties. 
(2) In the SOL tests carried out under the same series of loading conditions (A, B, C or D) and on the same material, $a$ versus $N$ relationships show that higher overload ratio, $R_{O L}$, caused more retardation effects. In addition, more retardation effects are observed for those overloads applied in the earlier stage of crack growth.

(3) In each SOL test, the overload applied in large$\Delta K_{A}$ region resulted in larger average crack growth rate, $\Delta a_{O L} / N_{O L}$, in the overload affected zone than that applied in small- $\Delta K_{A}$ region, where $\Delta K_{A}$ is the stress intensity factor range right before the overload application. Moreover, the absolute reduction of $\Delta a_{O L} / N_{O L}$ from CA level resulting from each overload was about the same.

(4) In the SOL tests, increasing overload ratio, $R_{O L}$, led to increased value of the non-dimensional variable, $1-\left(\Delta a_{O L} / N_{O L}\right) /(d a / d N)_{A}$, which is thought to be the relative reduction of fatigue crack growth rate following the overload. For SM520B, the average reductions at $R_{O L}=1.2$, $1.4,1.7$ and 2.0 were about $3 \%, 23 \%, 40 \%$ and $50 \%$, respectively. For SS400 and HT780, the average reductions at $R_{O L}=1.4$ were about $22 \%$ and $15 \%$, respectively.

(5) In the SOL tests, the overload affected zone size, $\Delta a_{O L}$, was normally larger than the Dugdale's plastic zone size, $\rho$. For HT780, this tendency was even more evident.

(6) In the SOL tests with $R_{O L}=1.4$, increasing stress ratio $R$ from 0.22 to 0.46 led to the decrease of the variable $\Delta a_{O L} / \rho$ from $100 \%$ to $60 \%$ for SM520B. However, it had little effect for SS400 and HT780.

(7) In the POL tests, larger interval between overloads caused more crack growth retardation effects. For $N_{b}=5 \times 10^{3}$ and $2 \times 10^{4}$ cases, the relative reductions on constant $C$ in Paris' equation from CA level were about $60 \%$ and $71 \%$, respectively.
ACKNOWLEDGEMENT: This research is a part of the research on the fatigue life evaluation of welded members subjected to large number of small stress ranges in the long fatigue life region. It was jointly supported by the Grant-in-Aids of Ministry of Education, Science, Sports and Culture, and the research funds from Nagoya Expressway Authority and Kozaikurabu. The authors thank to Professor A. Kondo of Meijyo University and Mr. S. Kainuma for their valuable discussion.

\section{REFERENCES}

1) Nishikawa, K.: Fatigue problems in highway bridges, Bridges and Foundation Engineering, pp.19-23, 1983. (in Japanese)

2) Japanese Society of Steel Construction: Fatigue Design Recommendations for Steel Structures (English Version), December, 1995.

3) Yamada, K. and Cheng, X. H.: Fatigue life analysis on welded joints under various spectrum loadings, Journal of Structural Engineering, JSCE, Vol.39A, pp.947-957, March, 1993.

4) Elber, W.: The significance of fatigue crack closure, Damage Tolerance in Aircraft Structures, ASTM STP 486, pp.230-242, 1971.

5) Cheng, X. H. and Yamada, K.: Fatigue crack growth rate measurement of structural steel under overload conditions, Structural Eng./Earthquake Eng., JSCE, Vol.11, No.1, pp.45s-52s, April, 1994.

6) Scheid, F.: Numerical Analysis, Schaum's Outline Series, McGRAW-HILL Book Company, pp.235-266, 1968.

7) Himmelein, M. K. and Hillberry, B. M.: Effect of stress ratio and overload ratio on fatigue crack delay and arrest behavior due to single peak overloads, Mechanics of Crack Growth, ASTM STP 590, American Society for Testing and Materials, pp.321-330, 1976.

8) National Research Institute for Metals: Fatigue crack propagation properties in arc-welded butt-joints of high strength steels for welded structure, NRIM Fatigue Data Sheet Technical Document No.3, 1984.

9) Dugdale, D. S.: Yielding of steel sheets containing slits, Journal of Mechanics and Physics of Solids, Vol.8, pp.100-104, 1960.

10) Newman, J. C., Jr.: A crack-closure model for predicting fatigue crack growth under aircraft spectrum loading, Methods and Models for Predicting Fatigue Crack Growth under Random Loading, ASTM STP 748, pp.5384, 1981.

(Received September 5, 1997)

\title{
単一過荷重および周期過荷重下における各種の構造用鋼の疲労き裂進展挙動
}

\author{
山田健太郎・曹秋良・奥原祐治・程小華
}

実働荷重による溶接構造物の長寿命域での疲労耐久性を精度良く評価する場合, 荷重の相互干涉効果を 考慮する必要がある. 本研究では， 3 種類の鋼材（SM520B，SS400, HT780）の中央切欠き試験片に, 定荷 重(CA), 単一過荷重 $(\mathrm{SOL})$, 周期過荷重(POL)を作用させ, その疲労き裂進展速度を測定し, 荷重の干涉効 果を評価した. 